\title{
THE EFFECT OF AN INTRAUTERINE DEVICE ON UTERINE WEIGHT AND WATER CONTENT AND ON GENITAL TRACT GLYCOGEN OF CYCLING, OVARIECTOMIZED, PSEUDOPREGNANT OR OESTROGEN-TREATED HAMSTERS
}

\author{
A. T. GREGOIRE* AND R. ANSBACHER $\uparrow$ \\ Department of Obstetrics and Gynecology, \\ University of Michigan Medical Center, Ann Arbor, Michigan \\ (Received 10th August 1971, accepted 20th May 1972)
}

\begin{abstract}
Summary. The presence of a unilateral IUD resulted in a uterotrophic effect in intact, pseudopregnant and ovariectomized hamsters with or without administration of $10 \mu \mathrm{g}$ oestrogen. The glycogen content of the uterine horn containing the device was significantly less during pseudopregnancy. While the genital tract responded to oestrogen administration with glycogen synthesis, there was no enhancement of glycogen synthesis with the IUD. No difference in uterine water content was discovered in the presence of the IUD.
\end{abstract}

\section{INTRODUGTION}

The IUD is a method of contraception which has been extensively investigated in many species in an attempt to elucidate its mode of action (El Sahwi \& Moyer, 1970).

The presence of a device does not inhibit characteristic cyclic vaginal changes (Orsini, 1965; Richardson \& Ansbacher, 1971) or decidualization in the hamster (Orsini, 1965). The decidualization in the rat uterus, however, may be inhibited (Speilberger \& Olewine, 1966), limited (Greenwald, 1965), or unaffected (Ichikawa \& Morioka, 1969) by the presence of an IUD.

One proposed method of action has been that the IUD enhances uterine sensitivity to circulating oestrogens (Brown-Grant, 1969). The administration of $0.2 \mu \mathrm{g}$ (Wrenn, Wood \& Bitman, 1969) or $1.0 \mu \mathrm{g}$ oestrogen (Joshi, 1970) to ovariectomized rats with an IUD increased the uterine glycogenic response.

The object of this experiment was to measure quantitatively the effect of an IUD on the weight and water content of uterine horns and the glycogen content of the genital tract during the preovulatory phase of the cycle, after uterine trauma, and following castration with and without administration of $10 \mu \mathrm{g}$ oestrogen.

\footnotetext{
* Present address: Margaret Sanger Research Bureau, Inc., 17 West 16 Street, New York, N.Y. 10011 .

$\dagger$ Present address: Brooke General Hospital, Fort Sam Houston, Texas 78234.
} 


\section{MATERIALS AND METHODS}

Forty-two, sexually mature, virgin female, golden Syrian hamsters, purchased from a commercial breeder and not germ free, were observed daily through two normal oestrous cycles. On Day 4 of the third cycle, each was fitted with an IUD. A 2-0 black silk suture was placed into the right uterine horn with a straight $2-\mathrm{cm}$ atraumatic needle. The IUD was inserted $0.5 \mathrm{~cm}$ proximal to the uterocervical junction and was anchored externally with a double knot on the antimesometrial surface $0.5 \mathrm{~cm}$ distal to the uterotubal junction. A sham operation was performed on the left uterine horn in similar fashion but the silk suture was removed after being threaded through the uterus.

Twelve animals with an IUD were observed for the characteristic vaginal cycle changes (Orsini, 1961). The animals were killed at 16.00 hours on Day 1 of the third cycle following the placement of the IUD. Ten hamsters were observed through two normal oestrous cycles subsequent to the placement of the IUD. They were mated with vasectomized males and the presence of a copulation plug was taken to indicate the 1st day of pseudopregnancy. On Day 4 of pseudopregnancy, laparotomy was performed and both uterine horns were scratched on the antimesometrial surface of the endometrium with a burred No. 24 needle. The position of the IUD was verified, the presence of corpora lutea was confirmed to ensure that the animals were pseudopregnant. They were then killed $72 \mathrm{hr}$ later.

Twenty hamsters were subjected to bilateral oophorectomy at the time of IUD insertion. Ten were killed 7 days later, while the remaining animals were given $10 \mu \mathrm{g}$ oestrogen intramuscularly 7 days after oophorectomy and were killed 24 hr later.

All animals were anaesthetized with intraperitoneal pentobarbitone sodium ( $8 \mathrm{mg} / 100 \mathrm{~g}$ body weight) and oophorectomy and laparotomy were performed under clean but not sterile conditions.

At autopsy, the uterine horns and samples of the cervix and upper vagina were rapidly removed and weighed to the nearest milligram. The tissue was hydrolysed in hot $30 \% \mathrm{KOH}$ and the amount of glycogen determined by the anthrone method (Seifter, Dayton, Novic \& Muntwyler, 1950). The water content of uterine tissue was obtained by drying an aliquot of tissue to a constant weight.

\section{RESULTS}

A significant unilateral increase in weight occurred in the uteri containing an IUD in all groups except the pseudopregnant animals (Table 1), in which both horns were submitted to uterine trauma. Ovariectomy decreased the weight of both uterine horns, but the weight of the uterine horn with the IUD was greater than that of the control $(P<0.01)$.

The presence of a device did not affect the uterine glycogen in the cycling animal. The glycogen content in the pseudopregnant group was significantly less in the IUD horn than in the control horn. Ovariectomy and subsequent oestrogen administration affected the glycogen content of both treated and 
control horns. The amount of glycogen in these groups was less than in the cycling, intact or the control uterine horn in the pseudopregnant animals, but oestrogen did increase the glycogen concentration of both horns above the spayed levels $(P<0.01)$.

TABLE 1

TISSUE WEIGHT, GLYGOGEN, AND WATER GONTENT IN THE GENITAL TRAGT OF HAMSTERS GONTAINING A UNILATERAL IUD

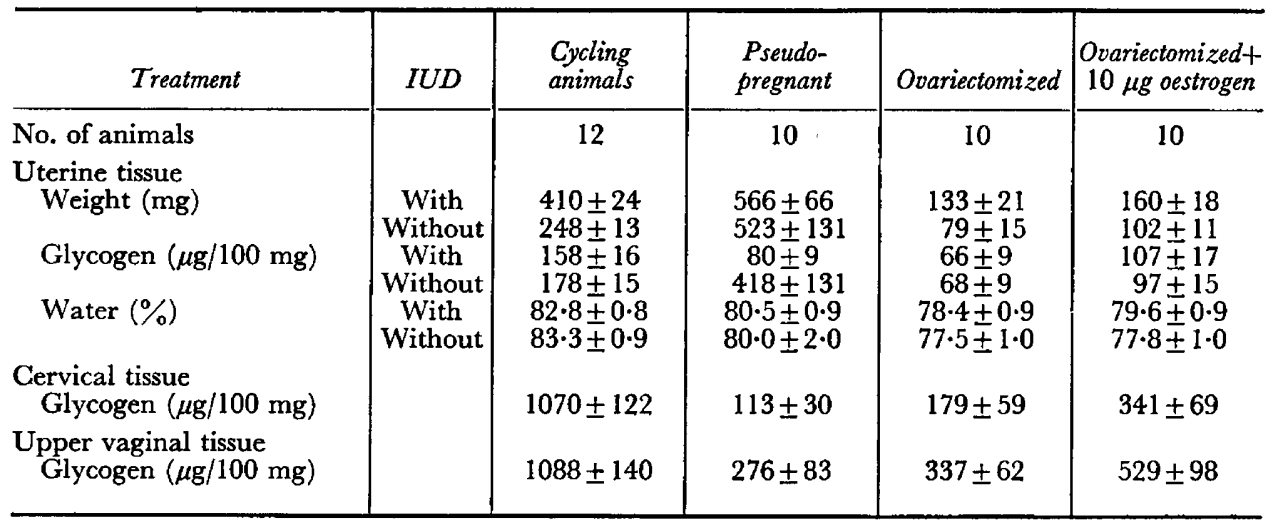

Values expressed as Means \pm S.E.M.

\section{DISCUSSION}

The presence of an IUD resulted in significant increases in the uterine weight of the intact cycling animals, and the uterotrophic effect was evident in castrates and enhanced by oestrogen administration. Unlike the rat, in which decidualization is partially inhibited by an IUD (Greenwald, 1965; Dizzia \& Bo, 1969), the process of probable decidualization, as determined by uterine weight, was not decreased or inhibited by the presence of a device.

The uterine glycogen is localized near the basement membrane in the epithelial cells. In the pseudopregnant rat, the uterine horn containing an IUD accumulated glycogen due to an inhibition of release (Parr, 1966).

Histochemical evaluation of glycogen in the bilaterally ovariectomized rat uterus had demonstrated that the greatest number of glycogen granules occurred at the site of the IUD in the circular layer of the mesometrial portion of the uterus (Bo, Moore \& Ashburn, 1969). The amount of granules was increased with progesterone administration but not with oestrogen. An increase in glycogen similar to that brought about by the IUD was demonstrated by inducing a leucocytic infiltration with the topical application of bovine serum albumin (Joshi, 1969).

In the pseudopregnant hamster group, the amount of glycogen was decreased in the presence of the device. In the pregnant rat, no differences were observed during either early or late pregnancy between control horns and those containing an intrauterine thread (Kar \& Kamboj, 1964).

In this report, the glycogen in the uterine horns of the intact, ovariectomized, or oestrogen-treated spayed hamsters was unaffected by the presence of an 
IUD. In the ovariectomized rat, however, the administration of oestrogen increased the glycogen content in the presence of an IUD. A $62 \%$ increase in glycogen content in rat uteri occurred with the IUD which was further enhanced by administration of $0.2 \mu \mathrm{g}$ oestradiol (Wrenn et al., 1969). A similar effect was reported with $1 \mu \mathrm{g}$ oestrogen (Joshi, 1970).

The glycogen content of the cervical and upper vaginal tissue did not differ significantly. The amount of glycogen was of the same magnitude as previously reported in the cycling (Gregoire \& Guinness, 1968), the pseudopregnant (Gregoire \& Richardson, 1970a), or spayed hamsters treated with oestrogen (Gregoire \& Richardson, 1970b).

There were no increases in the water content of any portion of the genital tract due to any treatment. Increase in uterine water content has been reported in the castrated rat as a result of an IUD (Joshi, 1970).

The effect of the IUD in hamsters is uterotrophic in all groups investigated and inhibits the synthesis of glycogen in the uterus during the pseudopregnancy.

The IUD did not inhibit the preovulatory increase of cervical and vaginal glycogen or produce changes either during pseudopregnancy or in the response to oestrogen of those tissues. The inhibition of glycogen synthesis by the IUD is restricted to the uterus during pseudopregnancy and, unlike that of the rat, is not enhanced by oestrogen administration.

\section{ACKNOWLEDGMENT}

This research was supported by a grant from The Population Council, New York, N.Y.

\section{REFERENCES}

Bo, W. J., Moore, P. J. \& Ashburn, M. J. (1969) The effect of a foreign body on the glycogen and sulfomucopolysaccharides of the uterus. Fert. Steril. 20, 351.

Brown-Grant, K. (1969) Effect of an IUCD on an endometrial response to steroid hormones in the rat. F. Reprod. Fert. $18,475$.

Dizzia, S. \& Bo, W. J. (1969) Local interference with deciduoma formation in the rat by an intrauterine foreign device. Biol. Reprod. 1, 391.

EL SAHWI, S. E. \& MoYER, D. L. (1970) Antifertility effects of the intrauterine foreign body. Contraception, $2,1$.

Gregorre, A. T. \& Guinness, B. J. (1968) Cyclic and pre-ovulatory changes in the glycogen content of the female hamster genital tract. 7. Reprod. Fert. 17, 427.

Gregorre, A. T. \& Richardoson, D. W. (1970a) The glycogen content of the early pregnant female hamster genital tract, the fertile conceptus and artificially-induced deciduomata. F. Endocr. 46, 9.

Gregoire, A. T. \& Richardson, D. W. (1970b) Glycogen and water responses to estrogen in the hamster reproductive tract. Endocrinology, 87, 1369.

Greenwald, G. S. (1965) Interruption of pregnancy in the rat by a uterine suture. F. Reprod. Fert. 9, 9.

ICHKAWA, S. \& MoRIOKA, H. (1969) Effect of an intrauterine foreign body on the decidual reaction in the rat. Int. F. Fert. 14, 154.

Joshi, S. G. (1969) Effect of an intra-uterine foreign body (IUFB) on glycogen accumulation and lysosomal enzyme activity in rat uterus. F. Reprod. Fert. 18, 170.

Joshr, S. G. (1970) Effect of a foreign body on responses of the uterus to estrogen in ovariectomized rats. Contraception, 2, 137.

KAR, A. B. \& KamboJ, V. P. (1964) Effect of an intrauterine device on gestation in rats. Indian $\mathcal{F}$. exp. Biol. 2, 229.

Orsins, M. W. (1961) The external vaginal phenomena characterizing the states of the oestrous cycle, pregnancy, pseudopregnancy, lactation and the anoestrus hamster Mesocricetus auratus Waterhouse. Proc. Anim. Care Panel, 11, 193. 
ORSINI, M. W. (1965) Effect of an intrauterine foreign body on the cycle and pregnancy in the hamster, Mesocricetus auratus Waterhouse. (Abstract). Anat. Rec. 151, 468.

PARR, E. (1966) Glycogen accumulation in the rat uterus containing an intrauterine contraceptive device. Fert. Steril. 17, 797.

Richardson, D. W. \& ANSBAcher, R. (1971) The effects of an intrauterine device on pregnancy in the golden hamster. F. Reprod. Fert. 25, 171.

Seifter, S., Dayton, S., Novic, B. \& Muntwyler, E. (1950) The estimation of glycogen with the anthrone reagent. Arch. Biochem. 25, 191.

Speilberger, A. E. L. \& Olewine, D. A. (1966) The effect of an intrauterine suture on pregnancy and deciduomata formation in the rat. Int. F. Fert. 11, 15.

Wrenn, T. R., Wood, J. R. \& Bitman, J. (1969) IUDs and the biochemical responses of the uterus to estrogen in ovariectomized rats. Biol. Reprod. 1, 234. 